\title{
A Place-Based Pedagogical Action Study to Enrich Rural Sustainability: Knowledge Ties of National Taiwan University's 10-Year Partnership with Pinglin
}

\author{
Shenglin Elijah Chang ${ }^{1,2, *(1)}$ and Ming-Yang Kuo ${ }^{2}$ \\ 1 International Degree Program in Climate Change and Sustainable Development, National Taiwan University, \\ Taipei 10617, Taiwan \\ 2 Graduate Institute of Building and Planning, National Taiwan University, Taipei 10617, Taiwan; \\ pomterg@gmail.com \\ * Correspondence: shenglin@g.ntu.edu.tw
}

Citation: Chang, S.E.; Kuo, M.-Y. A Place-Based Pedagogical Action Study to Enrich Rural Sustainability: Knowledge Ties of National Taiwan University's 10-Year Partnership with Pinglin. Sustainability 2021, 13, 2916. https://doi.org/10.3390/su13052916

Academic Editors: Jonathan London and Clare Cannon

Received: 20 January 2021

Accepted: 5 March 2021

Published: 8 March 2021

Publisher's Note: MDPI stays neutral with regard to jurisdictional claims in published maps and institutional affiliations.

Copyright: () 2021 by the authors. Licensee MDPI, Basel, Switzerland. This article is an open access article distributed under the terms and conditions of the Creative Commons Attribution (CC BY) license (https:// creativecommons.org/licenses/by/ $4.0 /)$.

\begin{abstract}
This study focuses on the loss of youth and talent as one of the most pressing social justice issues leading to unsustainable and inequitable development in rural communities. With the backdrop of the rapid decline in the young rural population and loss of local tacit knowledge, we question how to balance rural sustainability through place-based critical pedagogy by integrating rural societies, agri-economics, and cultural landscapes. To confront the crisis of a loss of young rural talent and local wisdom, interdisciplinary professors from the National Taiwan University initiated place-based pedagogical action research from winter 2011 to winter 2019. This interdisciplinary place-based pedagogy approach supported hundreds of students and educators by nurturing socio-cultural and economic networks that benefit both urban universities and rural communities. Using the curriculum outcomes of this study, we propose the concept of "Knowledge-Ties Youth Rural Sustainability" (KYRS). The KYRS framework addresses two questions: (1) how to bring young talent to rural everyday landscapes in order to sustain rural livelihoods, and (2) how to integrate rural tacit knowledge with contemporary sciences to create new technologies that sustain the environment. The KYRS framework serves as a pedagogical action research blueprint for university educators encountering similar rural challenges and opportunities to those faced by the National Taiwan University in Pinglin.
\end{abstract}

Keywords: social justice; social sustainability; rural communities; rural education; rural sustainability; youth engagement; talent flows; place-based critical pedagogy; action research; tacit knowledge

\section{Introduction: University Talent Flows for Social Justice and Rural Sustainability}

Although rural communities often occupy marginalized positions relative to urban centers, serving as natural resource extraction and waste disposal sites, well-preserved rural environments can also exhibit circumstances of social injustice due to the lack of vital economic resources for prosperous livelihoods. More importantly, when environmentally well-preserved rural areas confront a rural social unsustainable crisis, strategies like social movements and economic developments may not alter the fundamental challenges regarding the loss of populations and the lack of talent flows. Instead, universities and higher education may function as a critical mechanism in this response, acting as interfaces or channels to stimulate the flow of young talent between urban and rural areas. This study focuses on the loss of youth and talent flows as one of the most pressing social justice issues leading to unsustainable and inequitable development in rural communities. As a 10-year-long action-oriented case study, it sheds light on universities' social responsibility in incubating youth leadership in declining rural areas.

Environmental justice theories and practices from the U.S. have been influencing Taiwanese activists and scholars since the anti-DuPont movement in Lukang, a historical 
township in rural Changhua County of southern Taiwan, in 1986, before Taiwanese martial law was lifted. During that period, massive civic anger forced the Taiwanese government to halt the DuPont development project. One year later, the Bureau of Environmental Protection was officially established. As a developing society, Taiwanese environmental justice issues have been associated with hazardous waste, nuclear waste, industrial air and water pollution, and illegal high-tech dumping [1,2]. In some ways, Taiwanese environmental crises are similar to those in the U.S., in which race, gender, and class intersect with environmental inequality [3]. However, if we take a close look at the map of Taiwan, most contamination cases have occurred in rural and remote areas, including islands and peri-urban zones, in between urban and rural areas. This suggests that the spatiality of inequities between rural and urban communities forms the basis for environmental discrimination in Taiwan. Urbanized Taiwanese society expresses an underlying contempt for the rural countryside and its villagers. Urban-centered public policies dominate all dimensions of society, from public health and education to installations of infrastructure and competition for economic developments. This pattern in Taiwan is part of a larger trend of the privileging of urbanization and urban-centered lifestyles.

With the driving forces of the green revolution, agricultural mechanization, and urbanization after World War Two, rural regions declined, at first slowly and then with a more serious drop in the following half-century. Of the changes to rural regions, demographic decreases in young rural populations have damaged the health of rural societies the most, but more challenges are still to come. According to United Nations data, more than 50\% of the world population has resided in urbanized areas since 2007 [4]. This proportion is expected to increase to $68 \%$ by 2050 . Since the 1990 s, scholars have stated that rural communities as social systems must be able to resiliently regenerate and reproduce their socio-cultural and economic wellbeing within countryside landscapes [5,6]. Scholars argue that rural social sustainability should include local perspectives and be locally defined in order to meet the concerns of rural areas. Local livelihood, social participation, justice, and equity should all be part of rural sustainability $[7,8]$. Among the various contributing factors, the loss of rural youth and talent is a universally unsustainable and irresolvable condition that challenges rural societies worldwide. Rural communities have lost young talents who should supposedly take on the tasks of the past generation and inherit local wisdom, passing it down to generations to come. In reality, around the world, young farmers move out of their country homes and become urban-rural migrant workers in order to improve their living conditions. Their parents, aging farmers, may live alone in villages. Some young people may turn into the so-called "left-behind children", staying with grandparents in remote towns. The consequence is that when people move out of the countryside, these societies not only lose their population, but also lose the local wisdom and cultures rooted in these places. Various elements of rural and tribal tacit knowledge are also at high risk of being endangered. Thus, society must learn how to attract capable talents in order to sustain vital rural lives and re-innovate local tacit knowledge.

Indeed, the role of education has been overlooked within the discourse of rural social sustainability. More importantly, there is a gap between generating frameworks to assess rural communities' social sustainability and incubating supportive mechanisms to mobilize people and resources to liberate rural injustice. In this study, we aimed to bridge the two via developing a hands-on educational framework, in the form of action tools, for educators to activate their classrooms to balance urban-rural talent flows. For policymakers, social and environmental activists, citizens, villagers, and cross-disciplinary professionals, frameworks and index systems provide guidance to inspect and examine how their societies perform or how a particular event would impact their surroundings $[9,10]$.

Different ways of constructing pedagogical frameworks embed paradigmatic shifts regarding how we interact with communities and how we view ourselves within the communitybuilding processes. From the perspective of community resilience, Magis (2010) [11] suggested that, differently from community stability and community capacity, community resilience should react to systematic disruptions and responses. In public health and crisis manage- 
ment, we have been experiencing the COVID-19 pandemic since spring 2020. Cities and countries globally have been testing their community resilience, adaptation, and ability to transform in the process of coronavirus control and management.

The rural educational crisis of the loss of talent, local wisdom, and tacit knowledge is the norm in countryside communities worldwide. Unlike natural disasters and pandemics, which come with immediate and dramatic impacts, the loss of the rural young population silently develops into an irreversible phase, in which rural organizations are short of political and economic tools to manage their resources in response to the situation. Institutionalized and personal educational resources play a significant role in the rural sustainable ecosystem and enrich local wisdom. However, rural youth migrate to urban areas for educational purposes and then reside in cities. Taiwan has one of the lowest fertility rates in the world. Rural Taiwan has been losing youth and brainpower since the 1990s. Even worse, Taiwan will become a so-called "super-aged society" in 2026, that is, one with more than $20 \%$ of its population older than 65 [12]. There are pull-and-push driving forces that have led to the current rural phenomena. From a domestic socio-economic perspective, industrialization and urbanization have compelled young talent to migrate to cities in search of prosperity since the 1970s. From the perspective of rural villages, a lack of educational resources has pushed the youth to study in urban schools since the 1980s. Many rural districts in Taiwan, even within municipal governing systems, have closed public schools. In some cases, they do not have high schools (grades 10 to 12 in the U.S. system) to start with; this is the case for the Pinglin District, addressed in the following section. Educational facilities play a critical role in determining the forces that cause youth to emigrate from the countryside. These young people end up staying in their urban jobs or businesses and seldom return to rural family homes until their retirement. Their children are the first generation of urban-born people with rural-rooted parents and/or grandparents. Within three generations, children of the rural-rooted families have gradually lost their rural connections. Thus, society has not only lost rural communities but also their tacit knowledge, bounded in the local cultural and ecological heritage.

The super-aged rural Pinglin society, similar to the rural populations in Japan, Europe, and elsewhere, has a lack of resilient young talent in its communities. Arising from partnerships with National Taiwan University (henceforth, NTU) educators and students, this study responded particularly to the following youth and knowledge-based questions: (1) how to bring the young talent back to everyday rural landscapes in order to sustain vital rural livelihoods; and (2) how to integrate rural tacit knowledge in contemporary sciences to create new technologies that sustain the environment. The research case, Pinglin, is a well-preserved district that has confronted serious social and economic crises, especially due to the loss of its young population. Located in New Taipei City in northern Taiwan, Pinglin is a historical tea district covering about $160 \mathrm{~km}^{2}$ of mountainous area with less than five thousand villagers. More than $25 \%$ of the population is above 65 , making it a superaged society. In 1987, the entire Pinglin District was delineated within the Feicui Reservoir Fresh Water Protection Zone; therefore, all commercial and industrial developments have been banned since then. When the Highway 5 Bypass and Hsuehshan Tunnel were completed in 2006, the local tea business dropped to less than 30\%. Economic depression and development limitations have forced young generations to migrate to metropolitan areas to pursue personal and family prosperity [13]. In 2011, when researchers for this study visited Pinglin, hardly any teenagers or young farmers were seen in the neighborhoods. Thus, an NTU trans-disciplinary team-initiated place-based pedagogical action research from 2011 to 2019 that developed interdisciplinary classes, studios, and workshops to bring young talent to rural Pinglin.

Before moving forward into the action research, the analytical framework for rural Pinglin should be explained. Currently, scholars have proposed two conceptual models to analyze the interrelationships between social, economic, and environmental dimensions. The first model is structured as a three-layered sphere in which the environmental dimension, as the foundation, supports social and economic health and happiness. The second 
model portrays the three dimensions as overlapping circles. This paper, using the empirical data of rural Pinglin in Taiwan, applies the second overlapping circle model. The analytical diagram (Figure 1) illustrates the multiple layers of mechanisms integrating four aspects of curriculum transformations and place-based critical pedagogical evolvements [14,15]. The core of the diagram, the pedagogy of rural social sustainability, explains systematic steps and processes taken to cultivate place-based teaching curricula. Three essential methods are teaching support workshops, creating local connections, and developing curricula. All three set the foundations for professors interested in transforming traditional theoretical classes into place- and field-related classes. The second circle lays out the procedures and processes every teaching team should go through to understand how to collaborate with local communities. The four external boxes-economic enterprise, cultural cultivation, social regeneration, and ecological collaboration-are the results of the social design programs from the place-based critical pedagogical transformations.

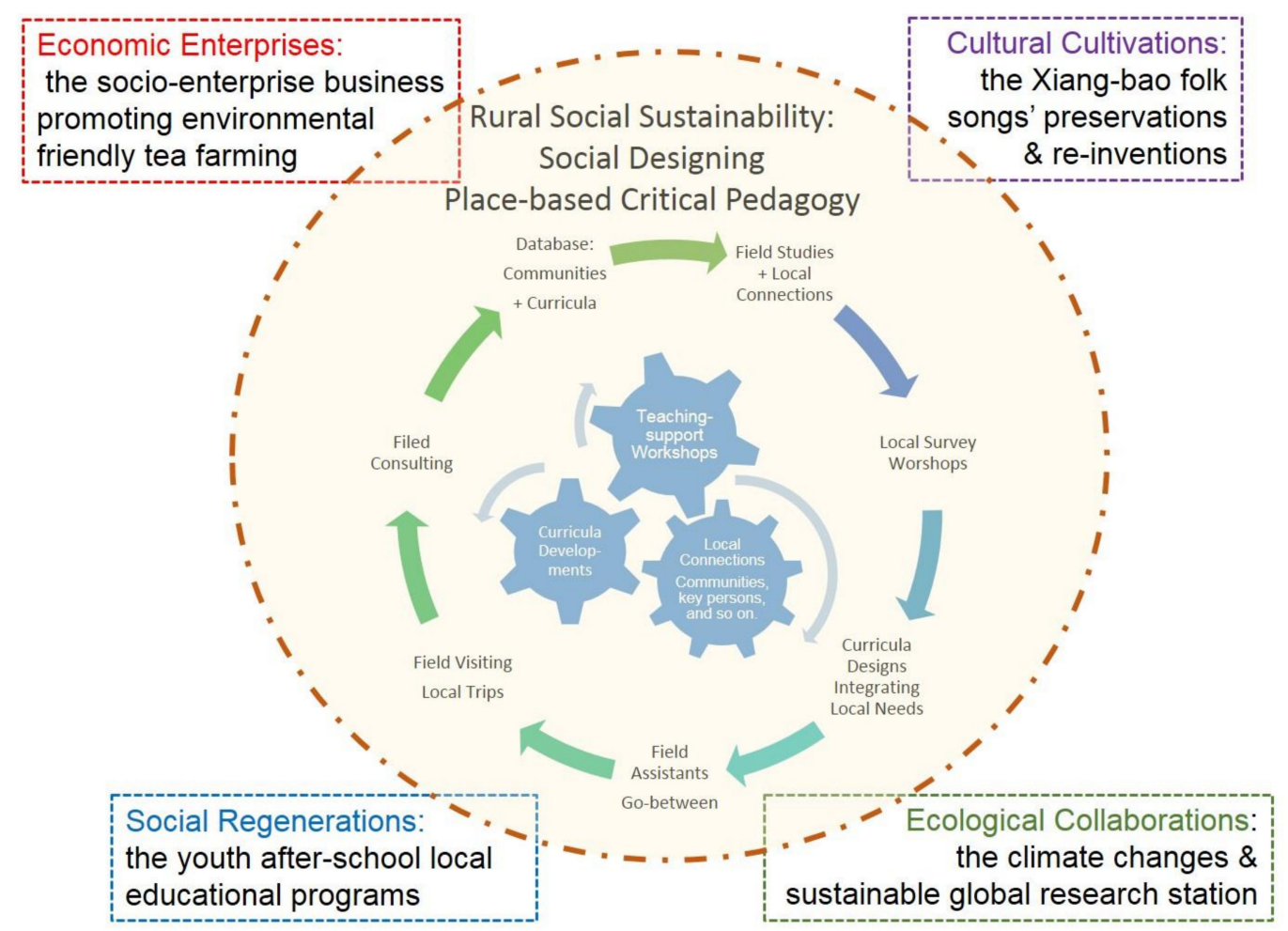

Figure 1. The multiple layers of mechanisms integrating four aspects of curriculum transformations and place-based critical pedagogical evolvements.

Under these circumstances, the pedagogical actions depicted in Figure 1 integrate the NTU teaching team's innovations across four categories of place-based classes to transform the disadvantaged Pinglin rural population. These four dimensions include economic, cultural, ecological, and social elements. First of all, economic enterprises promote environmentally friendly tea businesses that reduce chemical fertilizers and avoid pesticides. By doing so, Pinglin tea farmers can farm safely and not be harmed by chemicals. Eco-agriculture also improves the biodiversity of the entire Pinglin satoyama and preserves the holistic environments, preventing climate changes. For social regeneration and cultural cultivation, the related curricula improve social well-being via facilitating after-school educational programs and the artistic creativity of local folk music. More importantly, hundreds of interdisciplinary NTU professors and students have studied Pinglin's sociocultural, economic, and environmental dimensions during the ten years of the project. The knowledge ties between the NTU academic communities and Pinglin villagers has transformed the region's urban-rural networks. This study argues that rural inequality can 
only be modified when policymakers with both urban and rural experience understand and value the rural heritage and local wisdom.

Based on the analytical diagram in Figure 1, Section 2 elaborates on the site of Pinglin and the 10-year action research involving the place-based curricula. The core of Figure 1 describes the main content of this section. In Section 3, which presents the results, the four social-design dimensions (the four boxes surrounding the core of Figure 1, which are economic enterprises, cultural cultivations, social regenerations, and ecological collaborations) are analyzed. The four boxes of Figure 1 provide substantial curricula related to different dimensions of rural sustainability. In Section 4 the social design mechanisms that support the Pinglin transformation are analyzed. The social design mechanisms that integrate knowledge from NTU and Pinglin may act as models that inspire other rural communities to establish sustainable partnerships with universities. The 10-year action research of the NTU-Pinglin partnership, which aimed at revitalizing rural talent, concludes by presenting the "Knowledge-Ties Youth Rural Sustainability" framework (the KYRS framework), which educators can apply and refer to when they encounter similar rural challenges and opportunities.

\section{Materials: Case and Methods}

In this section, background on Pinglin, located in the New Taipei City of Taiwan, is introduced. Second, the action research method that the NTU team applied during this 10-year study is discussed. Place-based critical pedagogy was used as the philosophical blueprint to support the decade-long action research. Third, the essential theories applied in the study are elaborated upon, with a focus on social design and social innovation for sustaining tacit knowledge and scientific and professional knowledge within place-based critical pedagogies.

\subsection{Case: The Rural Pinglin Tea District, New Taipei City, Taiwan}

\subsubsection{Pinglin Tea District: Environmental Background}

Pinglin is known for two characteristics, (1) the Feicui reservoir, and (2) the Wenshan Baozhong tea plantation. The tea plantation terraces are often associated with this quiet periurban landscape (Figure 2). Pinglin is located in the northeast forested and mountainous area (reaching an altitude of $250 \mathrm{~m}$ to $800 \mathrm{~m}$ ) of the Taipei Basin within a portion of the Taipei Water Special Area (TWSA). The Feicui Reservoir has been providing fresh water for 6.7 million residents of Taipei, the capital, since 1987. All the townships within the TWSA zone are prohibited from developing any new buildings or industries. This new zoning control has been negative for the people living in the area but positive for the environment. The preservation of the natural environment has successfully sustained 316 animal species and healthy deciduous (broad-leaved) forests. Popular small-sized mammals include the civet cat, Formosan pangolin, emerald green tree frog, Muller's barbet, Formosan whistling thrush, alcedo (kingfisher), and Formosan blue magpie. The most famous tree species is the Taiwan acacia. Ferns are also very famous in this region because of the rainy climate.

Although the reservoir has significantly limited Pinglin's development and people;s quality of life, the popular Wenshan Baozhong has provided reasonable income for Pinglinians. Currently, $80 \%$ of Pinglinians work as tea farmers in the area. The remaining population is also associated with tea production and the tea business (Pinglin Township 2012). Due to its foggy and moist environment and hilly topography, Pinglin is one of the best oolong tea cultivation areas in Taiwan. The so-called conventional tea cultivation heavily applies pesticides and fertilizers to ensure that the tea leaves have a rich flavor. Therefore, even though the zoning control has restricted new buildings and industries from moving into Pinglin, its tea cultivation is toxic and pollutes the Feicui Reservoir [16]. 


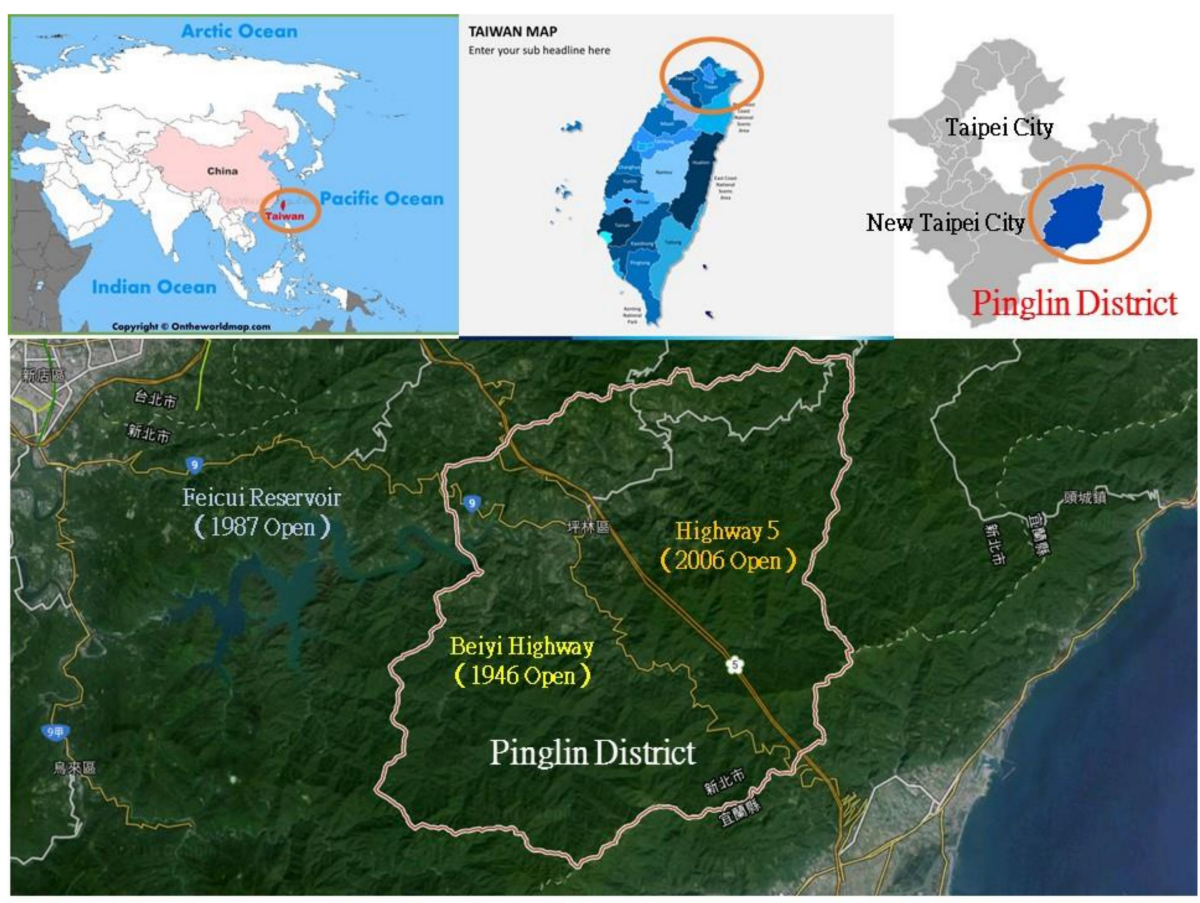

Figure 2. Geographical information and location of Pinglin District, from the regional scale of China, Taiwan, Taipei City, and New Taipei City. The Feicui Reservoir is also identified. The Pinglin District is located within the Feicui Reservoir.

The second phase of change ranges from 2002 and 2007, a period in which the Highway 5 Bypass and the Hsuehshan Tunnel (henceforth the HS Tunnel) were completed. On the one hand, the opening of the HS Tunnel disturbed Pinglin residents because of the east-west traffic between Taipei and the east coast of Taiwan. The local tea business relied on the passing traffic to die out after Tunnel 5 opened. On the other hand, residents expected that this would provide a way to acess Pinglin and believed it would bring tourists to Pinglin. However, Pinglin locals realized that there was no way for them to access the newly built highway and tunnel. They were extremely upset and mobilized to protest and request a highway exit. According to the Feicui Reservoir Freshwater Protection Zone Act, the Environmental Bureau does not want to add a Pinglin Exit. Government officials worry that the exit would bring too many tourists and automobiles to Pinglin, which would pollute the fresh drinking water. From 1999 to 2003, Pinglin local representatives mobilized tea farmers and villagers to protest. This led to a referendum, in which, among $64 \%$ of registered voters, $97 \%$ of them supported the Pinglin Exit. The Director of the Environmental Protection Bureau resigned and Pinglin gained a special exit, the Pinglin Interchange, with a limit of 4000 automobiles per day. Even though there were other symbolic aspects of Pinglin, such as their free drinking water and free health insurance, the locals believed the Pinglin Exit indicated Pinglin's prosperity. However, after the bypass opened, more young people left and only a few tourists arrived. This is connected with the issue discussed in the next section, the population [17].

\subsubsection{Pinglin Demographic and Educational Context}

Based on census data, two historical events impacted population fluctuations dramatically. Between 1975 and 1990, the delineation of the Feicui Reservoir Watershed Protection Zone influenced residents profoundly. In the 1980s, the central government concluded that the entire Pinglin Township should be under the Feicui Reservoir Fresh Water Protection Zone. To protect the freshwater quality, no developments were allowed thenceforth, while all Pinglinians with Pinglin household registrations received social welfare compensation. The lack of developments pushed many families to immigrate to other districts in New Taipei City. The compensations incentivized many Pinglinians to keep 
their household registrations in Pinglin, even though they had already relocated to other places. The construction of the Pinglin Interchange of the Highway 5 bypass, mentioned earlier, is the other significant event, of which the opening allowed more young people to leave and only a few tourists to arrive in the area. Thus, as a historical tea region regulated by the Feicui Reservoir Acts, there are no incentives for people to move unless they are extremely interested in learning the Baozhong tea craftsmanship or developing a tourist business related to tea. Although the household registration of the Pinglin population has hovered around 6000 since the 1990s (Figure 3), only about 5000 villagers live there. According to the New Taipei City 2019 demographic records, about $26 \%$ of Pinglinians are above 65 years old and thus it is considered a super-aging society [18]. In terms of education, $20 \%$ of Pinglinians have a college degree or higher, compared to the overall Taiwanese population, of which $47 \%$ have a degree. Due to its combination of education and age factors, Pinglin urgently needs talented youth to engage in and explore its intangible Baozhong tea heritage and the well-preserved cultural landscape of tea, along with the area's rich biodiversity.
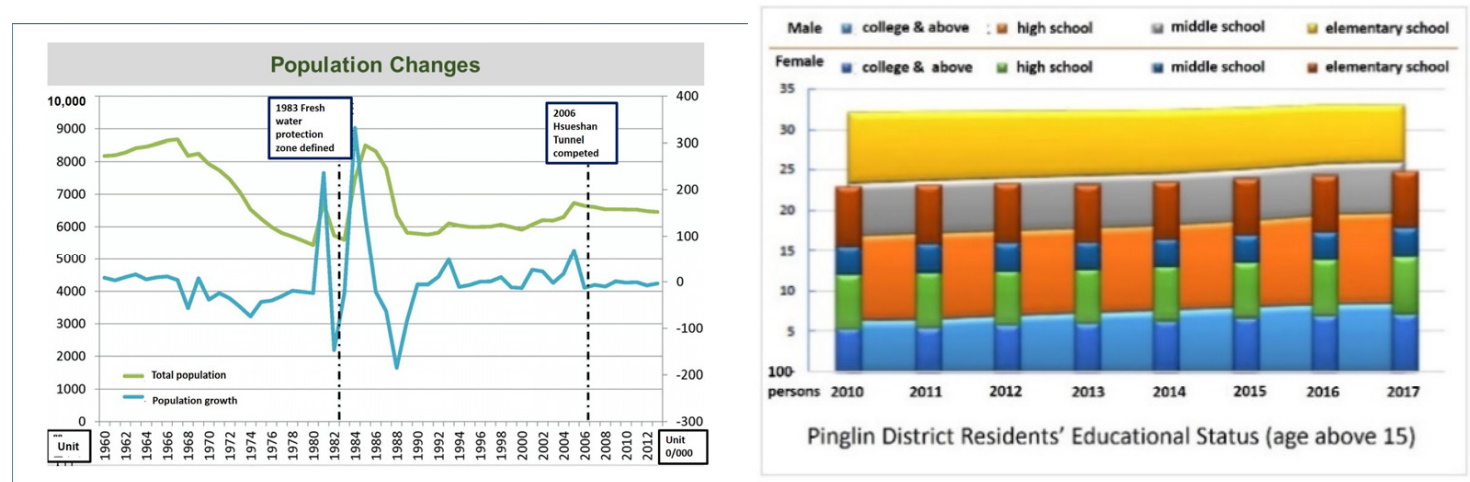

Figure 3. (Left) population fluctuations 1960-2012 and (right) gender-based educational data for residents above 15 years old, 2010-2017.

As mentioned earlier, Pinglin District is one of the areas that has never provided a high school education. Teenagers immigrate to other districts to attend high school due to otherwise long commute times. Usually, teenagers move out of their homes and stay with host families, typically their urban relatives, from their high school education until college. The youth of Pinglin are seldom seen on street corners, shop fronts, or trails in woods or farmlands in rural everyday landscapes; rather, they meander in metropolises, setting out their careers after they complete their education. Most of them end up staying in their urban jobs or business and seldom return to their rural family homes until their retirement. Their children become the first urban-born generation with rural-rooted parents and/or grandparents. Within three generations, children of the rural-rooted families have gradually lost their rural connections.

Researchers point out that small farmers with home-operation tea workshops dominate the tea-town landscape. Unlike tea industries in Natou in the south or Taidong in the east, where tea farmers sell their fresh harvest tea leaves to middle or large tea factories, Pinglin tea farmers make their own tea in their home workshops. In the past, every family member participated in the tea farming and making processes. Seniors recall how they sang the Xiang-bao folk songs to tease each other during the hard-working tea picking days. Men or fathers, as the household leaders of the families, are usually the ones that inherit the best tea-making craftsmanship. In his research, Kou names this phenomenon as the "tea household entrepreneur of Pinglin" and fathers as "Cha-hu-zhang" (leaders of tea household entrepreneurs) [19]. However, due to immigration between the 1980s and 2000, Pinglinian baby boomers, ranging from 50 to 70 years old, are the ones who grew up with the tea household daily culture. Those who were born after the 1980s, who are presently 
in their 40s or younger, may not be part of the tea household culture. The once-popular Xiang-bao folk songs are lost from Pinglinians' soundscapes [20].

\subsubsection{Taiwanese Tea and Wenshan Baozhong Tea Cultivation and Industry Background}

The Taiwanese prefer oolong tea. Researchers point out that nearly $70 \%$ of tea products consumed in Taiwan are oolong tea, of which $80 \%$ is Pinglin Baozhong tea [21]. The socalled Wenshan Baozhong tea (henceforth the Baozhong) is baked from Qingxin oolong tea leaves and ranked as one of the top 10 prominent teas in Taiwan. Dating back to the Qing Dynasty around the 1820s, Qingxin oolong tea trees were transplanted from the southern region of China by Pinglin tea farmers from Anxi in China. Unlike usual ballformed Chinese tea, Baozhong is known for its small spiraled-strip shape, the so-called little green dragon form. With its subtle honey taste, Wenshan Baozhong is popular with both Taiwanese and Japanese tea lovers. They appreciate the emerald leaf color with its elegant aromas and the golden greenish tea soup [22].

Tea is hard to cultivate, and it is especially hard to cultivate precious tea for discriminating Chinese tea lovers. Based on participatory observations and interviews, a study found that to preserve the extraordinary flavor and taste, the best tea leaves have to be juicy and free from pest bites $[23,24]$. Tea plants are the targets of more than 100 pests, which especially attack the plucking surface areas. One study by Kawai declares that the perennial and evergreen tea plants grow in the "most complex and most stable" agroecosystems among Japanese agriculture environments [25]. Most tea plant pests complete their life cycles within the tea fields. To establish eco-tea farming systems, one has to study the ecological chains of tea fields thoroughly. Kawai also argues that excessive insecticide applications might not be able to control tea pests because of the polyphagous nature of these insects. Instead, farmers should consider and experiment with the conservation and utilization of indigenous remedies in the control of tea pests. He recommends tentative "integrated pest management" (henceforth IPM) systems to be applied to Japanese tea cultivations. The Food and Agriculture Organization of the United Nations defines IPM as the careful consideration of all available pest control techniques [26]. The subsequent integration of appropriate measures discourages the development of pest populations and keeps pesticides and other interventions to levels that are economically justified and reduce or minimize risks to human health and the environment.

According to the field research, tea farmers usually prefer a conventional method of cultivating teas, because organic or environmentally friendly leaves would fall prey to bug bites. The bites not only damage the tea's flavor but also the beauty of the leaves. No organic tea brands could participate in local or national tea competitions under these circumstances. However, only competition tea can reap high profits in the Taiwanese and Chinese tea market [27]. In the case of Pinglin, only $6 \%$ of team farmers are organic or/and environmentally friendly. Mr. Lin, who is one of these farmers, only began cultivating eco-friendly teas after he was harmed by pesticides and hospitalized for a week. Lin says, "about three years ago, I only touched a very tiny amount of diluted pesticide; my whole body got reddish spots and an unendurable itch. I stay in hospital for a week. I never want to apply chemical stuff in my tea cultivations anymore" [28].

In addition to pesticides, fertilizers also cause problems. Tea farmers use a substantial amount of fertilizers to assure that they can harvest juicy tea leaves. Well-baked juicy tea leaves sustain good flavor even after being served several times. Tea masters indicate that high-quality tea leaves could be used as many as seven to eight times [29]. The Director of the Feicui Reservoir stated that "local tea farmers over-fertilize their farms. Tea trees cannot absorb so many nutrients. The extra nitrogen and phosphorus wash into the Feicui Reservoir and causes eutrophication in the reservoir." To address this issue, reservoir technicians have promoted the so-called "reasonable fertilization program" to tea farmers within the reservoir watershed. To date, dozens of tea farmers have joined the program, which has saved tea farmers money and reduced the level of eutrophication in the reservoir. 
In conclusion, within an evolving teaching and research journey, the NTU team set the goals of preserving and re-innovating tea farmers' tacit knowledge and local wisdom of tea farming and craftsmanship, along with the tea soundscape of Xiang-bao folk songs. The team also considered that children of the tea households deserved a better education. More importantly, scientists of the team decided to work with senior and experienced tea farmers to investigate the impacts of climate change on the local tea industry. Together, they experimented with different ways of cultivating tea plantations.

\subsection{Methods: Action Research}

Based on action research methods, the 10-year-long study had two phases, of which 2015 was the midpoint. Phase 1 ran until winter 2014, and Phase 2 began in spring 2015. Both phases integrated place-based critical pedagogy that engaged professors and students in the rural tea communities of Pinglin. The first phase, from winter 2011 to winter 2014, was the socio-enterprise-oriented period, whereas the second phase, from spring 2015 to spring 2019, was the agricultural-humanities-based period [30]. Action research is a self-reflective spiral of cycles of planning, acting and observing, reflecting, and then replanning in successive cycles of improvement [31]. Following this principle, both phases of the Pinglin action research went through the four-step cycle: (1) determining local challenges, (2) searching for solutions, (3) evaluating and reflecting on the outcomes, and (4) redefining new challenges. Step 4, redefining challenges, which was undertaken at the end of the first phase (winter 2014), interlocked with the first stage, defining problems, of the second phase (spring 2015).

The research team defined the challenges of the Pinglin tea town, including the economic, social, and environmental crises.

- Economic crisis

The freshwater catch basin limits the developments of all markets but the tea market.

- Cheap imported tea destroys domestic tea markets and prices.

- The Hsuehshan Tunnel and Highway 5 bypass limit the number of tourists and businesses.

- Social crisis

- The rural population has declined, and the cost of the tea industry has increased.

- Local tacit knowledge has been lost and there is a lack of younger generations that can succeed in the tea craftsmanship and tea cultural practices.

- Environmental crisis

- Climate change damages tea plants and production.

- Tea competition misleads tea farming to adopt unsustainable methods, and conventional tea farming especially pollutes freshwater.

Of the three intertwined crises listed above, the economic crisis was defined as the most urgent one. The place-based critical pedagogy used in the first phase emphasized incubating the entrepreneurship of a group of community-planning students. The research team decided to focus on issues related to promoting the tea business and ecologically friendly farming methods for the following three reasons. First, the Pinglin District cannot be removed from the Feicui Freshwater Protection Zone and the Hsueshan Tunnel and Highway 5 Bypass cannot be removed from the northeastern landscape of Taiwan. Thus, one must work within the local socio-economic conditions. Secondly, the team did not have expertise in areas such as increasing the rural population or reducing temperature fluctuations or the effects of global climate change. Thirdly, based on our participatory observations and interviews, the declining local tea business hurts villagers the most. The team thus committed to promoting environmentally friendly tea to alter the local farmers' perspectives of organic tea farming. Start-up tea companies were incubated from the researchers' rural revitalization studios. The start-up business actions and socio-enterprise experiments that the team undertook are described in Section 3. For the second phase, 
while environmentally friendly tea continued to be marketed, the rural revitalizations were extended into the social, cultural, and environmental domains. A group of climate scientists participated in the Pinglin curricula and started learning tea farming and tea making before setting up the micro-climate experiments. Musicians and social welfare teams also joined the rural revitalization actions.

\subsubsection{Phase One: The Socio-Enterprises Period, from Winter 2011 to Winter 2014}

Community planning and design studio pedagogy are the key mechanisms for the first phase (Figure 4). This section describes the tiers of curriculum transformations that the team went through. During the first phase, the curriculum transformations were within two types of community development studios, which the first author of this article developed. The first studio class was conducted in the Graduate Institute of Building and Planning at the National Taiwan University (BP-NTU). Place-based critical pedagogy is mainly used within the rural community course. Within the studio, the first author of this article also offered study abroad modules focusing on both Pinglin and rural cases in Japan and China for three semesters (listed below). Students visit rural areas in Japan, China, and Korea, which provides essential experiences needed to eventually start a tea business.

- $\quad$ Fall 2012: Five students (study abroad to Japan) plus two groups of Japanese classes visited Pinglin. Both groups learned about tea picking and weed management from local tea farmers.

- $\quad$ Spring 2013: Eleven students (study abroad to China) decided to market environmentally friendly tea by starting a tea company together.

- $\quad$ Fall 2013: Seven students (study abroad to Japan and Korea) developed strategies to sustain the environmentally friendly tea business. Two BP-NTU students from this studio establish an after-school program for the children of tea farmer families (service-learning zero-credit classes). This program is elaborated below in Section 3.3.

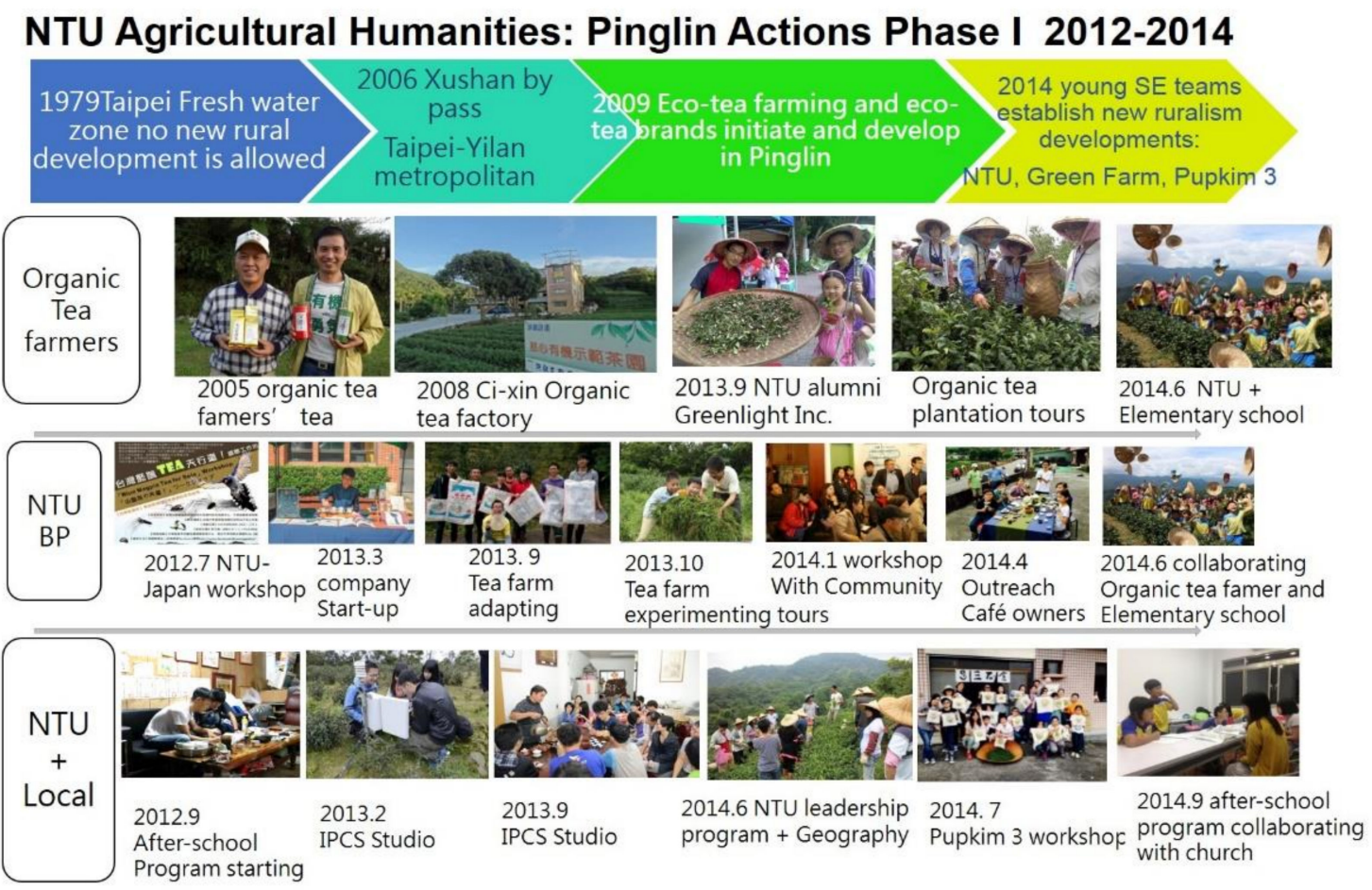

Figure 4. Action-oriented curricula implemented 2012-2014 (graphic prepared by the author). NTU, National Taiwan University; IPCS, International Degree Program of Climate Change and Sustainable Development. 
The second type of class the first author of this article experimented with during this phase was the transdisciplinary studio organized by the scientists of the International Degree Program of Climate Change and Sustainable Development (henceforth, IPCS). During this stage, all interdisciplinary professors first collaborated and visited Pinglin. Then, the professors' expertise was used to understand how to work together to help the Pinglin tea industry confront severe climate changes. All teams proposed projects related to tea businesses and activities with a lack of local climate change-related knowledge. The transdisciplinary studio was analyzed as part of the second phase because professors and students combined their local agricultural tacit knowledge with climate change science in the second phase in 2015. Based on these experiences, it was determined that issue-oriented transdisciplinary curricula required an overlapping period to examine and explore issues.

- $\quad$ Spring 2014: Seventeen students with different majors took the class. Students chose action-related topics to develop proposals to assist Pinglin's rural revitalization.

- Fall 2014: Fourteen students with different majors took the class. Students chose action-related topics to develop proposals to assist Pinglin's rural revitalization.

\subsubsection{Phase Two: The Agricultural-Humanities Period, from Spring 2015 to Spring 2019}

From spring 2015 to spring 2019, as a co-principle investigator of the NTU team, the first author of this article was in charge of the Agricultural Humanities Curricula Transformation Project (henceforth the Agricultural Humanities Project or the AH), which engaged 50 interdisciplinary professors to develop the so-called place-based critical pedagogy. This NTU team identified five rural and peri-urban communities to engage. All communities were challenged by economic and socio-cultural issues and Pinglin was one of the five. All 50 professors together offered more than 60 team-teaching classes that engaged 2300 students over six semesters. In Pinglin, 16 disciplinary professors offered 12 classes that brought about 240 students to study this small tea town. According the demographic data in 2017, this number reached a quarter of the college-education population in Pinglin. With the support of the Agricultural Humanities Project, one ecologically friendly tea entrepreneur team was incubated and one student club for Pinglin's rural afterschool education was developed. After completing the Agricultural Humanities Project, students initiated a business team and a rural education club, as they were committed to staying in Pinglin. Furthermore, climate-related researchers also continued to search for farmers to partner with to gather more micro-climate-scale local data. The efforts to blend local wisdom and scientific knowledge are elaborated upon in Section 3.

In the second phase (Figure 5), the NTU team emphasized the trans-disciplinary knowledge ties in order to move beyond the tea business and socio-enterprise experiments. Professors in the team came from the fields of human geography, political sciences, filmmaking, musicology, sociology, horticulture, social welfare, urban and rural planning, atmospheric sciences, as well as climate change and sustainable development. Among 240 students, about $70 \%$ came from three colleges- $40 \%$ came from the College of Sciences, $14 \%$ come from the College of Social Science, and another 14\% came from the College of Agriculture and Bio-sciences. The rest came from other colleges [30,32]. The courses included political ecology; filmmaking; musical innovation; storytelling; food agriculture and society; culture, society, and nature; climate change and the built environment; climate change in practice; as well as landscape and identity.

To sum up, based on Phase I and Phase II, professors and students collaborated with tea farmers and residents to develop the following major changes. 

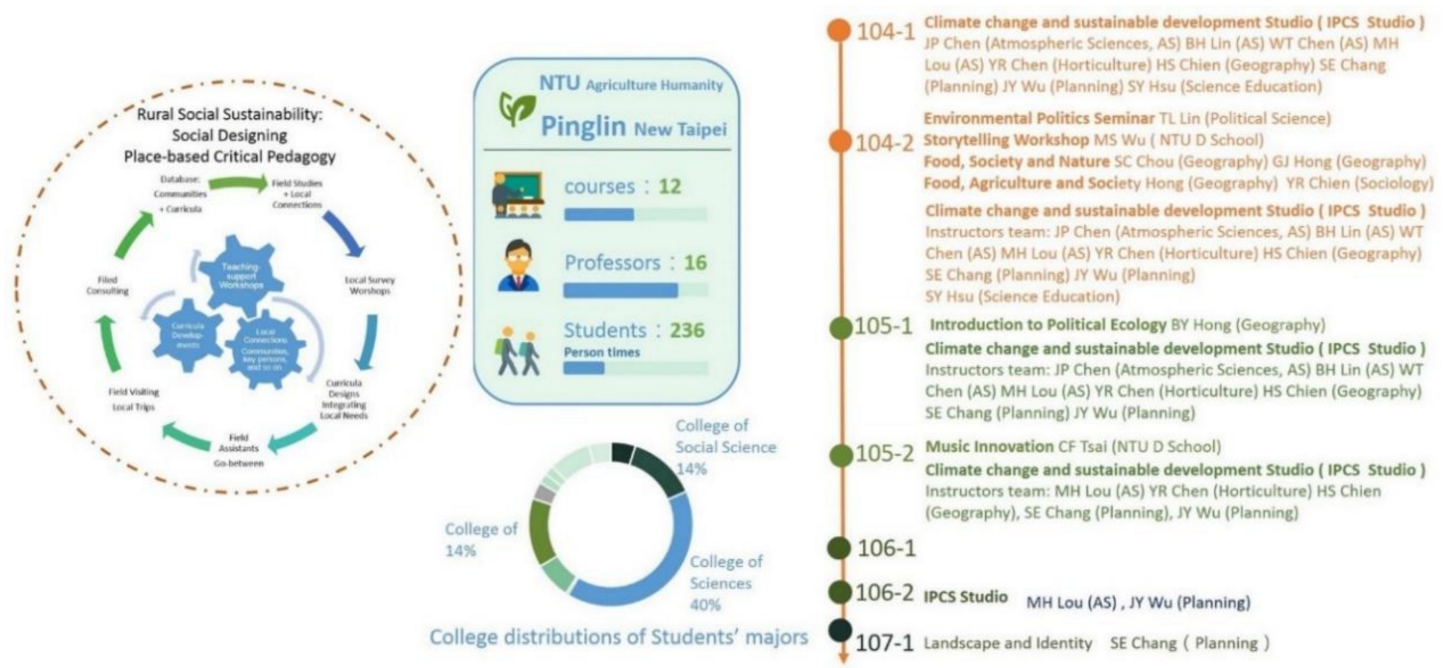

Figure 5. This figure elaborates how professors evolved their teaching in Pinglin, and provides the data relating to the curricula, as well as the professors and students coming to Pinglin because of the classes they took.

Socio-enterprise oriented: establishing two tea brands, "Blue magpie tea" and "Sanpuku tea" to market environmentally friendly tea from Pinglin;

- Education-oriented: New Buds Club's after-school programs for tea farmers' children,

- Cultural-related: preserving and regenerating Xiang-bao hip-pop; developing and promoting the Xiang-bao hip-pop music curricula for elementary and middle schools; - Scientific approaches: IPCS studio, research projects, and establishing the Pinglin global classroom.

\subsubsection{In-Depth Interviews of Seven Students Undertaking the NTU} Service-Learning Curricula

To better understand students' reflections and self-realizations, seven NTU students active in Pinglin were interviewed using snowball sampling from both phases by Professor Chen [32,33]. Some of them had never participated in an Agricultural Humanities Project (such as interviewees A and B), some had taken relevant courses (such as C), and some participants' activities in Pinglin were related to the Agricultural Humanities Project (such as D) or thesis research (such as E, F, and G) that they were conducting. The interview was conducted in a semi-structured manner, and questions included "Why did you go to Pinglin? What did you do in Pinglin? What did you learn from the place and people?" The interview was transcribed verbatim using electronic recording and analyzed through open decoding. All interviewees' motivations for participating in the Pinglin study were self-interested and beneficial to them, and the expected or actual benefits were relationshiporiented, such as caring about the situation of local children or the livelihood of tea farmers, or tool-oriented, such as applying or testing professional knowledge and skills to participate in the tea industry. Generally speaking, respondents who did not participate in the food and nutrition industries did not mention the idea of tool orientation, whereas those who did participate in these industries connected with the place from the beginning of the course. First, they wanted to learn things and gain knowledge. After gaining help from local people, they began to develop relationship-oriented actions, wanting to help the community or return favors.

\section{Results: The Place-Based Critical Pedagogy and Social Design of the Rural Pinglin Tea Town Transformations}

This section has four sub-sections, in which the societal impacts of the four actions that the NTU transdisciplinary team developed from 2011 to 2020, within the two phases introduced in the previous section, are analyzed. The four actions include (1) economic revitalization: socio-enterprise businesses promoting environmentally friendly tea and tea 
farming; (2) cultural revitalizations: Xiang-bao folk song preservation and reinvention; (3) social regenerations: the youth after-school programs run by the NTU New Buds Club; and (4) environmental/scientific collaborations: the climate change research station in the Pinglin tea town. Before describing each dimension of the four actions, the seven in-depth interviews of the students who joined the rural revitalization course and the after-school service-learning classes are addressed [30]. By using the seven students' reflections, this study presents the personal voices behind the actions they initiated and the journeys these interviewees faced. The seven interviewees participated in multiple actions, for example, initiating the tea business and after-school programs or studying climate impacts and the tea business, as well as the local folk music preservation programs. As one of the few pioneers of the Pinglin action, interviewee $F$ was involved in all four actions.

Interviewees E, G, and $\mathrm{H}$ came to Pinglin because of the rural revitalization course. As pointed out in the previous section, the studio is centered on the crisis of the Pinglin tea industry and challenges students to explore various ways of resolving the uneven economic development between urban and rural areas. The two-semester courses ended and students went in different directions. Interviewee $\mathrm{E}$ and several other students realized that production and marketing must be reconstructed to restore symbiosis between people and nature and that tea drinking is a living culture that needs to be revived, so they started a business that sells ecologically friendly tea. Interviewee $\mathrm{F}$ described his role change from taking courses to selling tea: "My attitude is quite different. I changed from passive to self-motivated and active. In the beginning, I just did whatever work was given to me. After my self-motivated experiences, I think about whether to initiate different projects or devote myself to several tasks. And then, my efforts finally come together." People such as Interviewees $\mathrm{F}$ and $\mathrm{H}$ are starting their businesses. Interviewees $\mathrm{E}$ and $\mathrm{G}$ tried to cooperate with Pinglin Church's supplementary classes in a service-learning course to bring in more NTU students to serve as elementary teachers for elementary school children. They continued to operate for three semesters before they felt like they were able to make the best of the situation and return the favor.

Interviewee $\mathrm{E}$ said that he did the tutoring work out of a sense of responsibility: "I think I should at least manage this matter for a long time. Whether I am doing it or not, at least a group of people must be in the local area. If I have promised something, I must at least complete it, that is, complete it to a certain level." Moreover, this social responsibility of responding to local needs after he used Pinglin as his thesis field, slowly turned into a relationship with his friends: "I feel that I am based on a straightforward attachment with local, that is, I have made some friends in the place ... I can't always put my friends aside; they have to continue to interact with them like this." After Interviewee E completed his thesis, Pinglin became another place to which he could go back to find old friends.

Interviewees A and B both came to Pinglin for service-learning classes. They both came to do something for the children in the area. They were both straight-A NTU students with strong academic abilities to tutor children. When children were doing their homework, the interviewees found that genuine care was the most useful tool for them. Thus, they piqued children's curiosity and allowed them to talk more about school and future ideas, which was not common to most people in Pinglin. Interviewee B left after a semester, and his concern for social welfare prompted him to turn to the path of social innovation and devote himself to another community by taking courses; Interviewee A stayed in Pinglin. He grew up in the middle of the countryside. When he went to the metropolitan area to study in high school, he said, "It was very tough for me ... but that kind of difficult work is not about learning demanding school projects ... just like myself, I do not know much about the nuances of urban cultures. It is very hard to explain my feeling." When Interviewee A came to Pinglin, he found that many children were very similar to him when he was a child. He hoped that he could act as a channel to let the children know more about the outside world. Interviewee $C$ has a similar background, but he only left home to go to Taipei when entering university, and he began to feel that he was incompatible with mainstream society and that he could not go back to his hometown. 
He hoped to improve the situation of Pinglin's children and his situation simultaneously, finding a new hometown and a sense of belonging.

\subsection{Economic Revitalization: Socio-Enterprise Businesses Promoting Environmentally Friendly Tea and Tea Farming \\ 3.1.1. Background of a Tea Socio-Enterprise Experiment}

In spring 2013, the socio-enterprise action was initiated after an accident in which the researcher's team failed to assist five tea farmers in selling $600 \mathrm{~kg}$ of ecologically friendly Baozhong tea to a national and well-known dealer. As the fair-trade principal increased the costs, the dealer abandoned the deal two weeks before the spring tea harvest. After brainstorming and discussing, the team decided to sell the tea on its own and thus had to establish a company to operate sales legally. To reduce the business cost, an e-business was chosen in which the NTU students were part of the team and promoted the tea via social media. Quickly, several mainstream news channels started following the project and reporting on it nationwide. Through e-commerce, social media, mainstream newspapers, and TV programs, the tea business gained momentum (Figure 6). From the researcher's community revitalization courses, two companies focusing on ecologically friendly tea brands were incubated in 2013 and 2015. By 2016, the Agriculture Department of New Taipei City identified that 33 local young tea farmers returned to Pinglin and operated their family tea business and farm with their parents. This young group named themselves the New Tea Generation. Even though the tea business still has issues, both companies have survived for more than 5 years. More importantly, the local young tea farmers have reclaimed their sense of ownership over Baozhong tea making and craftsmanship.

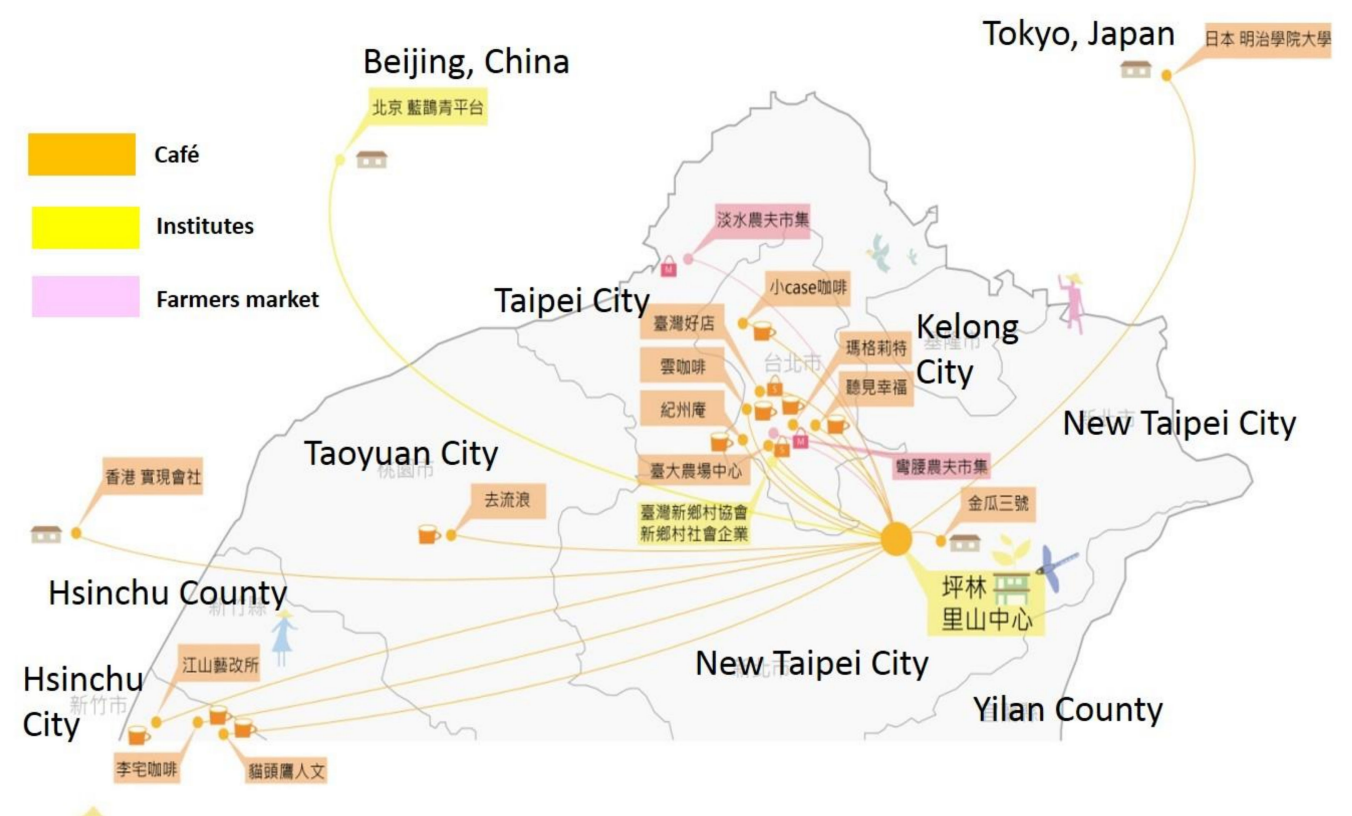

\section{3-14 Café shops support Pinglin NTU-BP environmental friendly tea}

Figure 6. In the very beginning, Café Support Tea (CST) was the strategy for the young NTU team to promote the ecofriendly Pinglin tea to the public. The pink and orange color dots indicate Café shops carrying the eco-friendly tea. All shops' names were in Chinese.

\subsubsection{Pedagogical Transformations Incubating the Tea Socio-Enterprise}

In terms of the place-based critical pedagogy, rural revitalization, and the actors who engage in the revitalization processes were all important for the Pinglin program and the researchers' team. The team studied the failed and successful cases of agriculturalbased rural revitalization, while also aiming to understand the personal transformations of 
the actors' lifestyles and career journeys. The study-abroad community course was used to cultivate the NTU tea business team. Case studies were undertaken in Japan, Korea, and China during the three semesters of the course. The team conducted the following case studies to study agricultural and business strategies: the Toyooka stork rice case (Japan) [17], the slow food and slow life of Awaji Island (Japan), organic tea farming in Nara (Japan), the art festival revitalizations of Seto Sea (Japan), the Han-Nong-Han-X of Satoyama Ayabe (Japan) [34], social enterprise visits in Seoul (Korea), and the Xucun Rural Art Festival in Shanxi (China) [35].

Two of the most inspiring and comprehensive cases were the (1) Stork preservation capital Toyooka and (2) the Han-Nong-Han-X Ayabe (which literally means part-time farming and part-time working on other jobs). Toyooka City has spent 50 years restoring the extinct oriental stork to ensure that it would fly back into the city's sky. To do so, the municipal government restructured its governmental structure by re-inventing rice farming methods; nurturing stork-friendly rice farmers' networks; incubating environmentally oriented businesses and industries; and transforming the educational curricula to embrace stork-centered environmental materials and programs. In the Han-Nong-Han-X Ayabe city project, Shiomi San emphasized two dimensions pertaining to developing individual lifestyles and career commitments, which were critical to the young students in the NTU teams. First, people in Han-Nong-Han-X farm part-time and spend the rest of the time using their talents to make a living. Shiomi San believes that everyone should try to engage in farming to establish a personal relationship with the land and appreciate mother nature. Secondly, Shiomi San and key people of the Ayabe city project developed the Satoyama network that allowed people with talents to relocate to Ayabe, thus confronting the city's serious population decline and aging issues. Volunteers of the Satoyama network provided jobs, housing, education, and even local customs-related support and advice to potential newcomers. Even though they prefer young couples with children, they actively do outreach to potential migrants with different professional backgrounds and age distributions.

Once the team learned about the model of nurturing an eco-system to cultivate rural products, they understood that the Pinglin project would be a decade-long one. The purpose of the project is not short-term profit. However, some profit must be made to sustain the eco-friendly tea business. From Han-Nong-Han-X and the Ayabe Satoyama network, the team recognized that everyone makes career choices based on their conditions. The choices might change and the journey might alter, especially in the case of the NTU team, of which members comprise around twenty and thirty young men and women, respectively. They may change their career routes or encounter personal or family situations that impact their Pinglin action. Based on this line of thinking, it was understood that the resilient socio-enterprise actions needed flexibility and networking flows.

\subsection{Cultural Revitalizations: The Preservation and Re-Invention of Xiang-Bao Folksongs \\ 3.2.1. Background of the Tea Folksong Preservations}

The cultural revitalization of the Xiang-bao folk songs (equipment to a type of "folk hip-pop" in which tea farmers complimented tea-leaf-picking women) started from a conversation between the principal of the Pinglin Elementary School and the research team. The principal told the team that they had not been able to find any music teachers for a long time, and thus the team decided to invite Taiwanese musicians trained by the Yale School of Music to Pinglin. Collaborating with the elementary school and the Wives' Club of Pinglin Business District, a tea-picking event and concert were hosted on 10 May 2012, the Yale alumni international volunteer day. Professor Tsai, the flutist, fell in love with Pinglin during that visit. Following the concert performance, Tsai set Pinglin as her class field to collect folk songs and the sounds of the landscape. By coincidence, students of her class discovered fragmented spectrums of the Xiang-bao folk song and told Tsai that there were too few materials to be re-composed. However, when Tsai read through the spectrum carefully, she realized that the scrappy sounds and lyrics were a treasure trove for 
Taiwanese folk music. Therefore, she devoted her teaching in the following four semesters to the preservation and re-invention of the Xiang-bao music.

\subsubsection{Pedagogical Transformations of the Tea Folksong Preservations and Re-Inventions}

During the four semesters focusing on the Xiang-bao folk music transformations, Tsai organized a unique project to produce concerts and a video jockey (henceforth, VJ), showing the most popular and cutting-edge music, film, and television in combination with her innovative musical creation course at NTU Design School (henceforth NTU D School). The Xiang-bao folk song suddenly transformed from a dying-away vocal sound into a fashionable composition, integrating sound and visual arts. Inspired by the Xiang-bao VJ performances, the principals of the Pinglin Elementary School and Junior High School decided to include the Xiang-bao folk song programs into their curricula. More importantly, young composers and lyricists also wrote songs to praise Pinglin. In the Xiang-bao concert of April 2016, Pinglin's primary and middle school students performed with Rene Izquierdo, a Spanish guitar composer, and Tsai in the KHS Musical Hall in Luzhou, New Taipei City. The majority of the audience were Pinglin residents. They expressed their Pinglin pride and identities during the performance. Outside the venue, NTU D School students used Xiang-bao songs to create various game modules.

The Xiang-bao folk music album and Tsai were nominated for the traditional and cross-discipline award at the 29th Golden Melody Awards in 2018 (Figure 7). In 2012, the team first learned that Pinglin Elementary School could not hire a full-time music teacher. By 2018, the situation had gradually improved within the local school curricula. However, from the perspective of the global soundscape, Tsai was aware of the challenges of the inheritance and innovation of the Xiang-bao song. Compared to the value put on puppet shows or Taiwanese operas, Taiwanese society does not understand the special cultural values embodied within the Xiang-bao song. In contrast, when Rene, the foreigner guitar master, uploaded an acapella version of Grandma Huang's Xiang-bao singing on his Facebook, Rene's non-Taiwanese-speaking friends around the world "liked" the Xiang-bao song right away. Tsai argues that it is Taiwanese people who do not know the value of Xiang-bao songs, which are the most ancient and classical folk music generated from tea cultural landscapes.

As an internationally renowned flutist, Tsai understood how unique local cultures play crucial roles in extending the Taiwanese cultural soundscapes to the rest of the world and intertwining past and future aspects of Taiwanese tea cultures. In her radio interview, Tsai emphasized that the distance between Pinglin soundscapes and global tea cultures is not a physical matter but is related to how to distribute resources for distinguishing certain types of cultures. Ever since Tsai discovered the Pinglin Xiang-bao music, she was fully committed to having her classes conduct fieldwork to study the music and the stories of the only four singers left. Based on the students' creative projects, she promoted Xiang-bao music via VJ projects, award-nominated albums, international-quality concerts, and TV and radio interviews. She also compiled an intangible cultural heritage application for Xiang-bao music and submitted it to the Cultural Department of the New Taipei City. Although the committee rejected her inquiry in 2018, she was appointed as the chair of the department the following year. During the period of Tsai's Xiang-bao music preservation and re-invention, the elementary and middle high schools of Pinglin adopted the Xiang-bao music within their curricula. 
Pinglin's Xiang-bao Folk Music nominated for the $29^{\text {th }}$ Golden Melody Awards in 2018

Prof. Tsai collaborates with local seniors, Pinglin Middle School, Rene Izquierdo ( Spanish guitar composer) and NTU students

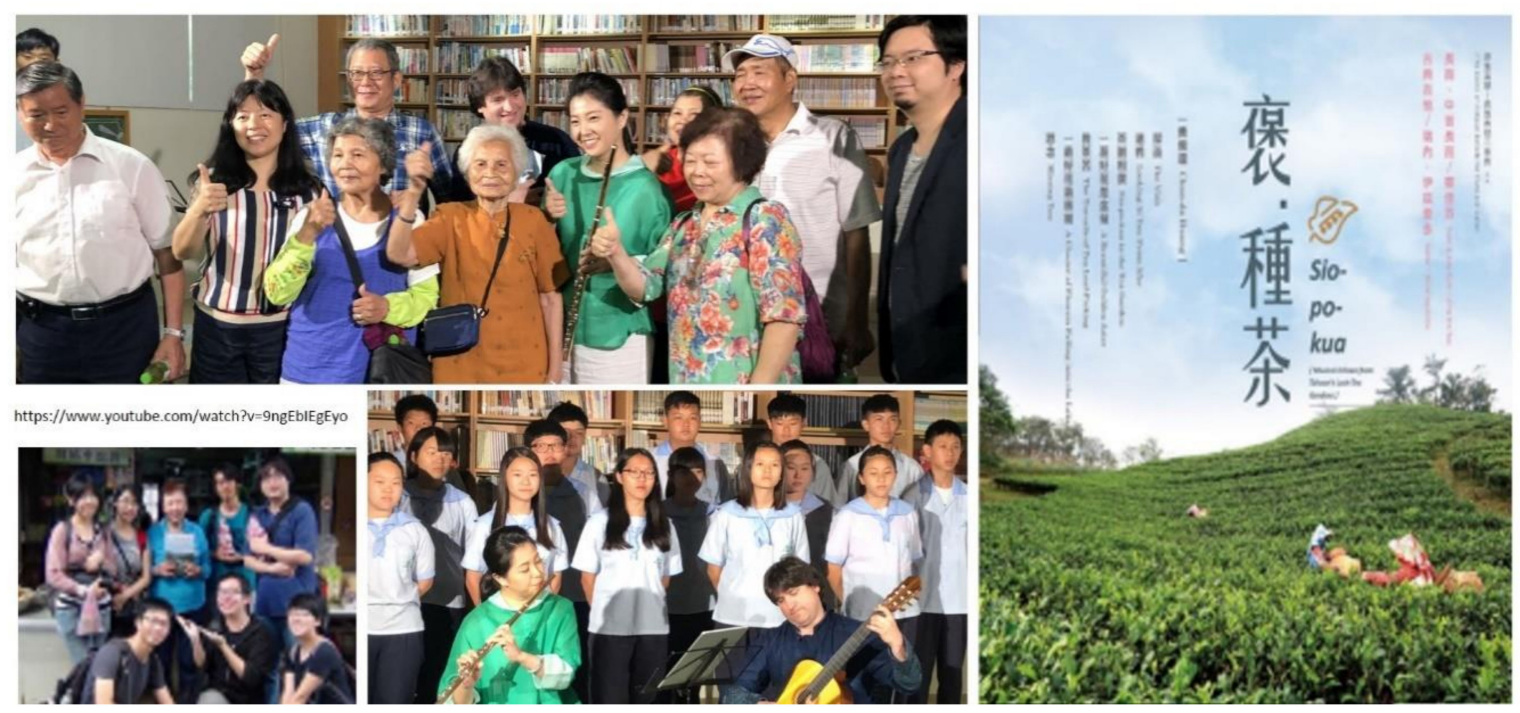

Figure 7. Ever since Tsai discovered the Pinglin Xiang-bao music, she was fully committed to having her classes conduct fieldwork to study the music and the stories of the only four singers left. Based on the students' creative projects, she promoted Xiang-bao music via video jockey (VJ) projects, award-nominated albums, international-quality concerts, and TV and radio interviews. The poster (in Chinese) of the right side were the advertisement of the Xiang-bao music concert that Prof. Tsai and Mr. Izquierdo performed in the New Taipei City.

\subsection{Social Regenerations: The Youth After-School Programs Led by the NTU New Buds Club 3.3.1. Background of the After-School Programs}

After-school programs were first initiated in 2012, when the research team realized they needed to better understand tea households and family lives and that children of tea farmers needed tutoring for their homework. Beginning in 2012, Interviewee $G$ transported volunteer tutors twice a week to Pinglin to work as class assistants. At that time, five tea farmers lived on five separate hills. Interviewee $G$ used his aging car to drop tutors, oneby-one, at each farmer's home to teach their children. By the time he dropped off the last tutor, it was almost time to go back to pick up the first one. Since then, the NTU-Pinglin service-learning classes have operated for 8 years (Figure 8). The services have changed from home tutoring to church-supported programs, whereas core students established the Xinya (which literally means "new buds") club in 2016. The turning point was in 2014 when Pastor Z from Pinglin's Presbyterian Church came to the team to discuss how to combine the church counseling course (started in 2011) and the NTU tutoring program using NTU students as primary teachers. In 2015, Professor Chen from the department of social work decided to use Pinglin as the location of her action research and university services. Since 2015, teaching teams from the social work department have become the core of Pinglin's after-school programs. By 2017, teaching assistant L proposed the idea of establishing a students' club for the Pinglin after-school program. This could enable students to make decisions about service-learning classes and curricula. In 2018, LL decided to relocate to Pinglin after graduating from NTU. The Xianya Club continued the afterschool service-learning class. 
NTU "New Bud Club" for Pinglin's youth after school partnership Developed from service-learning course in Dept. of Social Work

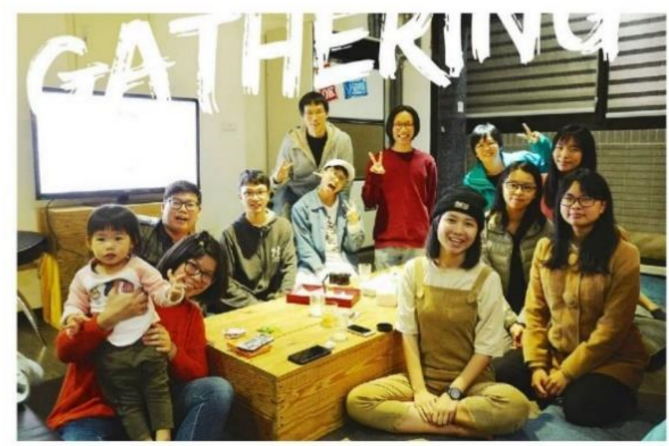

Within 30-minute driving distance from NTU, Pinglin's educational resources are much behind Taipei City

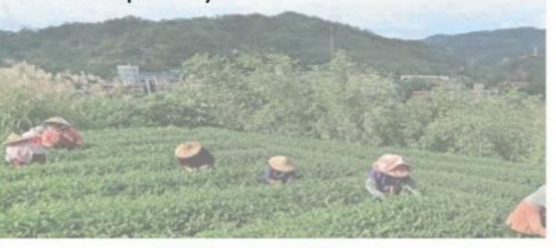

Call for participants Pinglin Service Learning Program

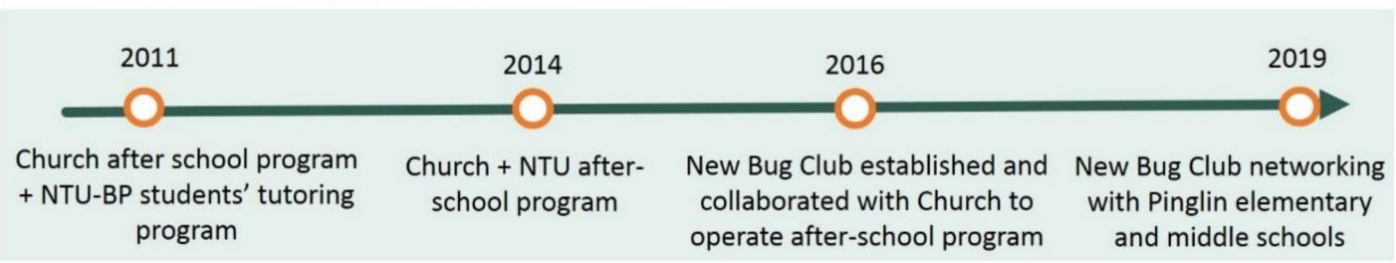

Figure 8. Timeline since the NTU team entered Pinglin in 2011. The after-school classes were initiated in 2012 as private tutoring services. Service learning is the key mechanism for the university side to sustain the partnership with the local church and schools.

3.3.2. Teenagers' Networking with Outside and NTU Tutors' Friends and Families of Pinglin

As the key person in the Xinya students club and the Pinglin after-school program, Prof. Chen has been committed to working with rural disadvantaged families since she was in college. Based on her experiences, NTU students have to empower themselves to lead the service-learning programs. Only once students identify themselves as teachers for tea farmers' children can they establish supportive partnerships. Most local children attending the tutoring programs come from disadvantaged families, living, for example, with grandparents, newly immigrated mothers, or low-income parents. Tutors have to pay more attention to these children but should not pity them. The children need to learn how to mobilize resources by themselves. Both children and tutors need to learn how to interact with each other. Therefore, in addition to tutoring sessions, the NTU tutoring teams arrange BBQ picnics, home visits, potluck gatherings, mini-trips, and overnight workshops with the children. Tutors observe that children gradually change from quiet and shy to lively and chatty by the end of the semester. Sometimes, children become attached to their tutors and even seem to manipulate them. Some tutors who are from rural areas support the children as if they were their younger siblings. LL mentioned that he was a very shy child when he first arrived in the big Taipei City from his countryside hometown in the south. He wants to bring children of the tea town of Pinglin to Taipei to explore and understand urban life and culture. By doing so, LL hopes that the Pinglin children will not be as embarrassed as he was when they move to cities.

Prof. Chen has been in contact with NTU tutors, local children, and pastors of the church since 2015. She believes that rural after-school service-learning programs are a long-term commitment. It takes time to develop and nurture these programs. Since 2013, when the first group of children was supported, until now, seven years have passed. The older children have already completed their college education. The first group of tutors who invited Prof. Chen to Pinglin also moved onto new chapters of their lives. G works in a computer company in Taiwan; $\mathrm{H}$ returned to Guangzhou in China to practice community planning; and J is doing a Ph.D. program in Japan. Every semester, about 15 tutors arrive in Pinglin. The Xinya Facebook club functions as an online forum in which all past and present members can communicate. Currently, there are 176 members. In this forum, tutors 
of alumni often "like" the photos and stories posted by Prof. Chen. Recently, the Xinya Club has filmed the Pinglin Junior High School clubs' events, including those of the cycling clubs, hockey clubs, Feiyang clubs (orchestras), badminton clubs, etc. By posting the films on the Pinglin Da-Xiao Shi (Chores of Pinglin) Facebook page (which has 2166 members), most adults and parents in Pinglin see how the youth play and exercise on campus. These films also represent memories recorded by NTU tutors for the teenagers in Pinglin Junior High School. During the recording process, tutors said that they began to understand the multifaceted life experiences of Pinglin teenagers.

\subsection{Environmental Scientific Collaborations: The Climate Change Research Station in Pinglin 3.4.1. Climate Change Scientists Bringing Students to Pinglin to Study Tea Town Adaptations}

The International Degree Program of Climate Change and Sustainable Development (IPCS) consists of professors from various disciplines, including atmospheric science, geoscience, life science, forestry and resource conservation, human geography, landscape architecture and community planning, and political science. The IPCS emphasizes interdisciplinary pedagogy to support local communities' adaptation to climate change. In 2013, JP, the IPCS director, decided to contribute to the activities in Pinglin action program and developed courses in the fall and spring semesters for students to learn how climate affects the local tea industries. The content of the course was designed for learning on a global and local scale. Globally, an Intergovernmental Panel on Climate Change (IPCC) report published by the United Nations Intergovernmental Committee guided students to understand why the IPCC report was essential and how to use the report to establish a common language for subsequent implementation. Pinglin covers the middle and low altitude areas of a satoyama (a Japanese term applied to the border zone or area between the mountain foothills and arable flat land) in the Snow Mountains. The pollination, flowering, fruiting, and harvesting of tea trees are related to the temperature, humidity, light, and rainfall. Therefore, students and professors in the courses discussed the rainfall, temperature, cloud and fog, and sunlight patterns in Pinglin over the past 10 years. The class cohorts tried to address how rapid climate changes would affect the industry and environmental ecology of the Pinglin Tea Township-How do Pinglin tea farmers cope with unusual climate phenomena? How are tea trees and different species growing in the Pinglin satoyama? More importantly, how could IPCS scientists assist tea farmers to develop resilient farming in unpredictable situations? From the spring of 2013 to the autumn of 2018, each semester, dozens of students with different majors engaged in fieldwork in Pinglin. They bumped into tea farmers and their children. Students spent time and drank tea with senior farmers and listened to how the farmers changed tea species to adjust to the weather. Students also joined farmers during the spring tea harvest season and tried to learn the craftsmanship of tea making. Drinking tea and conversing as part of their daily tasks in tea plantations, senior tea masters, climate researchers, and students with different majors explored various ways of blending tacit knowledge with professional technologies.

\subsubsection{Pinglin-Born Urban-Grown Youth Bridging Sciences and Local Wisdom}

The key person assisting with developing the knowledge ties between students and the community was Mr. K, who did so in the spring of 2015. K was a Pinglin-born and Taipei-grown plant scientist and artist, aged in his twenties, who always wanted to start a business in Pinglin. K had an understanding of both NTU's curriculum design and farmers in his hometown, so he took the class as an audited student and introduced NTU professors and students to master tea farmers aged in their 60s and 80s. Based on the senior tea farmers' field records and in-depth interviews, the students have been able to fuse scientific and tacit knowledge. With K's help, the course teaches that the life of tea has three aspects-first, planting tea, in which the generation of tea trees depends on the heavens and the land; second, making tea, in which the tea-making technology after harvesting depends on people; third, tasting tea, in which people have additional 
discussions on tea and art. Based on this understanding, they developed the Pinglin tea cultivation knowledge map and the Pinglin tea folk calendar, integrating people, plants, and environments (Figure 9). The team also produced a 3-D map that analyzes tea species and planting methods in ancient and modern times from the perspective of soil types, drainage treatments, cultivation methods, and weather and rainfall data surveys. The class survey found that Pinglin originally had nearly 100 native tea species. However, Qingxin Oolong, a very delicate species of tea, was the only type allowed in the tea competition established in the 1980s. Therefore, other tea species declined dramatically. Qingxin Oolong tea plantations now dominate the Pinglin landscape. Qingxin Oolong is prey to many diseases and insects and is not drought-tolerant. It is not easy to grow organically and is not suitable for Pinglin. Due to climate change, summer temperatures in Pinglin have increased, and the amount of clouds and fog has decreased. Compared to the period from 2004 to 2013, in 2014 the rainfall patterns of autumn to summer have also changed, impacting tea production time and quality.

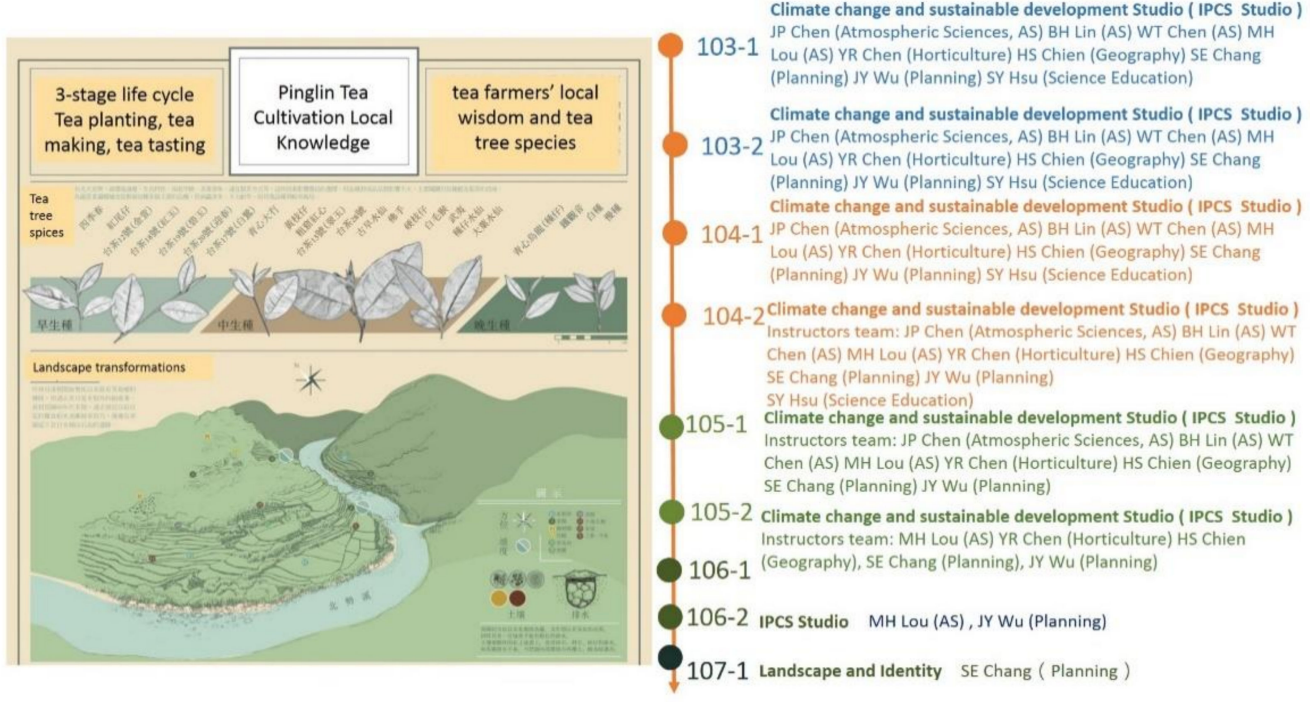

Figure 9. Integrating local senior tea farmers' farming diaries and interviews, the IPCS team developed the Pinglin tea cultivation knowledge map and the Pinglin tea folk calendar integrating people, plants, and environments.

Based on K's group research, students in courses run the following semester progressively explored the relationship between tea cultivation methods, tea varieties, and climate change. In the following three semesters, students discovered that, due to climate change, in recent years, Pinglin tea farmers had to use extensive non-irrigated farming methods and began to use water pipes to change the direction of mountain springs and receive rainwater. Rising temperatures have also changed the patterns of pests and diseases. Qingxin Oolong varieties are more delicate and not as resistant to drought and pests as the Jinxuan and Sijichun varieties. At the same time, organic cultivation helps the roots of tea trees penetrate deep into the bottom layer of the soil and absorb groundwater. Compared to wild grass cultivation, weeds more or less surround the tea trees during the hot summer period, reducing the surface temperature and evaporating the already-thin water vapor, thus mitigating the impact of drought on tea plants. The class outcomes included collaborations with tea farmers, the Pinglin youth, and IPCS professors and students. The courses have managed to retrieve the tacit knowledge that has faded during the period of agricultural modernization and recorded the scientific knowledge of the community. Students have understood the most crucial aspects of the tea life-cycle and then reconnected the lost relationships between tea, people, and the natural environment, simultaneously addressing the challenges of climate change. This kind of knowledge transformation is valued as scientific research and has attracted the attention of researchers from the Central Weather Bureau. They have 
cooperated with teachers of a communication course for the Department of Atmospheric Sciences to collect more local meteorological data in Pinglin.

\section{Discussion and Conclusion: University-Based Partnerships for Rural Social Sustainability}

The declining population and the loss of young talent generates conditions of social injustice for rural areas. To resolve this challenge, our research addressed two questions: (1) how to bring young talents to rural everyday landscapes to sustain rural livelihood; and

(2) how to integrate rural tacit knowledge with contemporary sciences to create new technologies that sustain the environment. This paper presents the 10-year-long journey that the NTU team has undertaken in the Pinglin tea-growing area. In retrospect, all stakeholders who participated in Pinglin were motivated by their own interests and by doing what was beneficial to them. They were co-creating the social space of Pinglin through educational events [36]. The expected or actual benefits depend on the stakeholders' relationships with Pinglin, whether they care about local children's situations and the livelihood of tea farmers or are interested in tea craftsmanship. Both students and instructors appreciated learning local tacit knowledge and gaining local wisdom. After getting acquainted with the local people and being helped by them, the research team began to develop relationship-oriented actions, wanting to be helpful to the community or give back to it. After investigating the two phases of the NTU-Pinglin action research undertaken from 2011 to 2019, this study identified four dimensions, elaborated in the previous section, relevant to the research, namely, (1) socio-enterprise of an ecologically friendly tea business, (2) cultural preservation and re-invention of Xiang-bao music, (3) after-school youth program and service-learning classes, and (4) climate change science for local tea farming. In this study, we have analyzed the mechanisms that assisted rural Pinglin to regain its rural sustainability. Each of the four dimensions has the following key components:

- At least one instructor has committed to the dimension; for example, Tsai committed to Xiang-bao music, Chen to after-school service-learning programs, JP to climate change and ecological tea farming, and the author to socio-enterprise eco-friendly tea business.

- Local institutions and villagers have responded to the NTU actions, joining in with them or initiating their own actions:

Inspired by the NTU tea brand, more than 30 young tea farmers have reformed their family-based tea business.

- NTU service-learning students have established their own after-school club to support the youth of Pinglin. The local church also collaborates with the NTU students club.

- Local schools have accepted Tsai's Xiang-bao music curriculum and made the course a requirement for students.

- Young scientists have established their coursework in Pinglin. Working with local tea farmers, they have systematically conducted studies on micro-climate data and local tacit farming technologies.

Proposition of the "Knowledge-Ties Youth Rural Sustainability" Framework (KYRS Framework), Facilitating Partnerships between Universities and Rural Communities.

Based on the decade-long NTU-Pinglin experiment analyzed in this paper, we found that in order to preserve and improve rural sustainability in the shrinking countryside, university educators need to confront their teaching and research boundaries and find new ways to have students approach local knowledge. It is critical to detach from one's discipline and observe, listen to, and analyze the particular issues within the community, and that researchers try to engage with their knowledge. From this common ground between the community and researchers, professors can mobilize their college students to initiate their study plan and discover how the local wisdom of the communities might stimulate their interests and curiosities. By making students curious and motivated, they begin researching and working in these communities on their own. Based on the 
curriculum outcomes and discussions presented in this paper, we proposes the KYRS framework to facilitate academic communities when university educators encounter similar rural challenges and opportunities. A three-fold supporting system structures the KYRS framework (Figure 10).

The framework is based on the intersection of five broad questions (5-W): How, Why, Who, Where, and What. "How" includes various methods used to achieve educational purposes, for example, transdisciplinary curricula, issue-oriented events, learning actions, and participatory engagements. "Why" refers to local issues, including things such as aging, educational, and craftsmanship-related issues. "Who" documents actors, i.e., local officials and key personnel covering young talents, mid-career U-turn or I-turn villagers, and local families. "Where" documents the locations where teaching and learning are taking place. "What" defines the goals of the place-based curricula, for example, social or cultural sustainability and economic strategies. Every part of the 5-W categories are associated with specific elements that facilitate the teaching and learning activities at the particular locations. Within the 5-W categories, each $\mathrm{W}$ dimension is associated with different characteristics of factors that need to be addressed. For example, under goals related to the "what" category, the characteristics suggested here include (1) theories and literature; (2) laws, regulations, policies, etc. in particular contexts; (3) tools, methods, technologies, etc. in particular contexts; and (4) tacit knowledge and local wisdom in different cases. The five categories are the foundation for social sustainability goals, cultural sustainability, economic sustainability, and ecological sustainability. Alternatively, the teaching teams could add their particular goals and related characteristics that they consider essential for their contexts. The KYRS template connects these 5-W categories with border questions and details of doable suggestions generated on the basis of the 10-year experience of the Pinglin research project. The template is not a set of universal guidelines. Educators and teaching cohorts could take the liberty to modify and invent their own templates.

In conclusion, universities and higher education institutions must provide rules and regulations to support social responsibility-based teaching that allows instructors to decide which communities to work with and select topics freely. Then, an advanced teaching team that has community work experience must provide the new instructors with place-based information and nurture them to ensure that they gradually familiarize themselves with the tempo of teaching outside the classroom. Following these steps, local agents and actors must effectively communicate with teaching teams and students at the beginning of the teaching period. Instructors, teaching assistants, and key agents of communities should keep an open attitude and adjust to changes at all times. Through substantial fieldwork and different assignments, students and the locals can develop many action plans. Local people's social networks are essential for instructors and students to develop knowledge-based innovations. During the innovative processes of the centerlesscurriculum approach [37], students may discover career opportunities, whereas professors may establish research projects to contribute to communities. Finally, curriculum-based preservation and the re-innovation of tacit knowledge and intangible heritage are the core of universities' social responsibilities pertaining to rural sustainability. The knowledge ties between rural communities and universities will sustain the diverse cultural heritage of generations to come. 


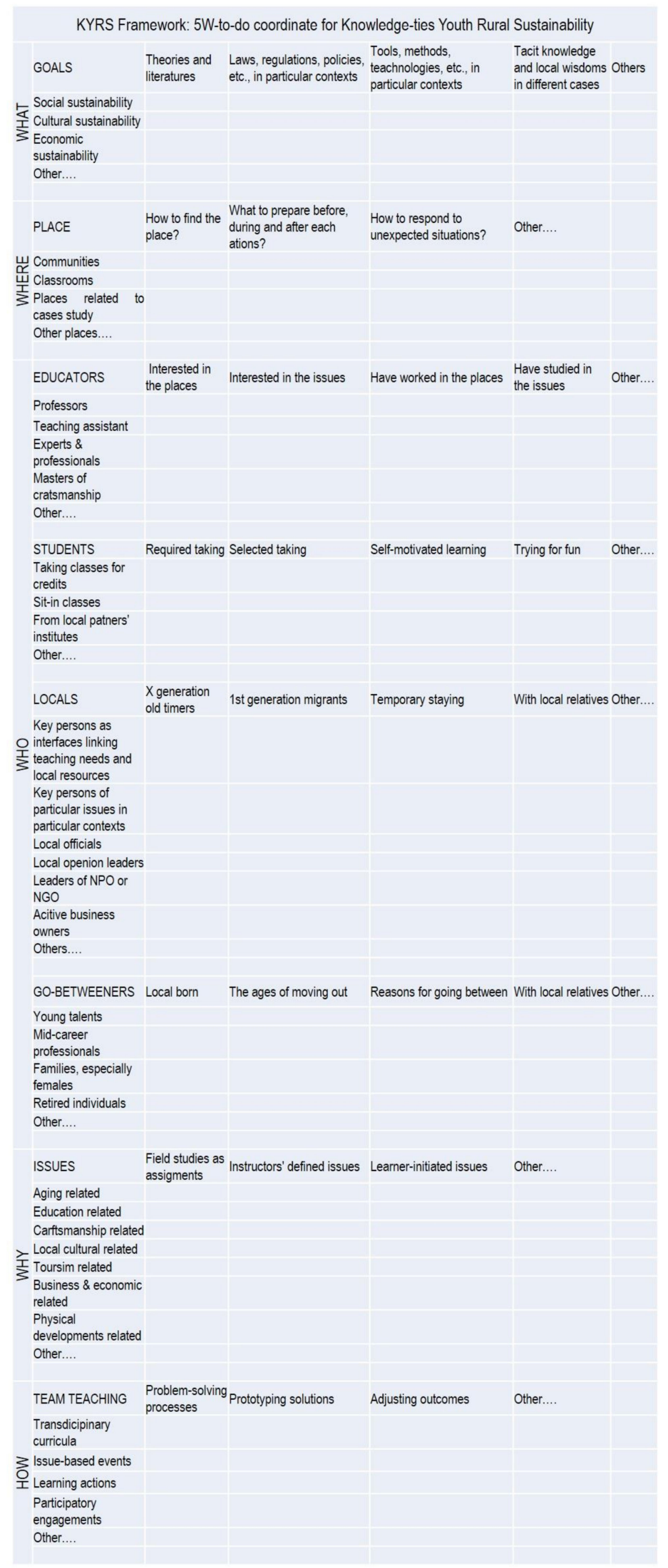

Figure 10. The Knowledge-Ties Youth Rural Sustainability (KYRS) framework used to facilitate academic communities when university educators encounter similar rural challenges and opportunities. The 5-W (How, Why, Who, Where, and What) to-do categories for the Knowledge-Ties Youth Rural Sustainability framework. 
Author Contributions: Conceptualization, S.E.C.; methodology, S.E.C.; software, M.-Y.K.; validation, S.E.C. and M.-Y.K.; formal analysis, S.E.C.; investigation, S.E.C. and M.-Y.K.; resources, S.E.C. and M.-Y.K.; data curation, S.E.C. and M.-Y.K.; writing-original draft preparation, S.E.C.; writing-review and editing, S.E.C.; visualization, M.-Y.K.; supervision, S.E.C.; project administration, S.E.C.; funding acquisition, S.E.C. All authors have read and agreed to the published version of the manuscript.

Funding: From 2012 to 2013, this research was funded by Ministry of Science and Technology (competitive grant number NSC102-2410-H-002-158-MY2). From 2014 to 2019, this research was funded by Ministry of Education, Department of Information and Technology Education, the multipleyear HFCC competitive grants.

Institutional Review Board Statement: This 10-year-long study was conducted prior to the IRB requirements of both funding agencies in Taiwan. There was no more than minimal risk to subjects and that participants of the research are within a cultural group within which signing a form is not a normal practice.

Informed Consent Statement: Written informed consent has been obtained from the patient(s) to publish this paper.

Data Availability Statement: All data analyzed in this study is presented in Tables in the text was obtained from publicly accessible databases cited in the text.

Acknowledgments: The authors would like to acknowledge the contributions of the project team, Agricultural Humanities at NTU as a whole, and the decade-long partnership with Pinglin tea farmers, families, Pinglin Elementary School, Pinglin Junior High School, and the Presbyterian Church in Pinglin, Taiwan. The authors are also grateful to two anonymous reviewers for their comments. The authors would particularly like to appreciate 16 professors and 263 students who participated in and contributed to the curriculum transformations in Pinglin from 2011 to 2019. Special appreciations toward Jin-Yong Wu (Co-PI and project manager from 2013 to 2017) and Sheng-you Hsieh (Co-PI and project manager from 2017 to 2019).

Conflicts of Interest: The authors declare no conflict of interest. The funders had no role in the design of the study; in the collection, analyses, or interpretation of data; in the writing of the manuscript, or in the decision to publish the results.

\section{References and Note}

1. Chang, S.; Chiu, H.-M.; Tu, W.-L. Breaking the silicon silence: Voicing health and environmental impacts within taiwan's hsinchu science park. In Challenging the Chip: Labor Rights and Environmental Justice in Global High Technology Industry; Smith, T., Sonnenfeld, D., Pellow, D., Eds.; Temple University Press: Philadelphia, PA, USA, 2006; pp. 170-180.

2. Tu, W.-L. IT Industrial Development in Taiwan and the Constraints on Environmental Mobilization. Dev. Chang. 2007, 38, 505-527. [CrossRef]

3. Brulle, R.J.; Pellow, D.N. ENVIRONMENTAL JUSTICE: Human Health and Environmental Inequalities. Annu. Rev. Public Health 2006, 27, 103-124. [CrossRef] [PubMed]

4. United Nations Department of Economic and Social Affairs, Population Division. World Urbanization Prospects: The 2018 Revision (ST/ESA/SER.A/420); Department of Economic and Social Affairs, Population Division: New York, NY, USA, 2019 ; p. 103.

5. Smailes, P.J. The enigma of social sustainability in rural Australia. Aust. Geogr. 1995, 26, 140-150. [CrossRef]

6. Jones, R.; Tonts, M. Rural restructuring and social sustainability: Some reflections on the Western Australian wheatbelt. Aust. Geogr. 1995, 26, 133-140. [CrossRef]

7. Scott, K.; Park, J.; Cocklin, C. From Sustainable Rural Communities to "Social Sustainability": Giving Voice to Diversity in Mangakahia Valley, New Zealand. J. Rural Stud. 2000, 16, 433-446. [CrossRef]

8. Chambers, R.; Conway, G.R. Sustainable Rural Livelihoods: Practical Concepts for the 21st Century; Institute of Development Studies, Universty of Sussex: Brighton, UK, 1991; p. 33.

9. Atanda, J.O. Developing a social sustainability assessment framework. Sustain. Cities Soc. 2019, 44, 237-252. [CrossRef]

10. Cole, L. Assessing Sustainability on Canadian University Campuses: Development of a Campus Sustainability Assessment Framezork; Royal Roads University: Victoria, BC, Canada, 2003; p. 66.

11. Magis, K. Community Resilience: An Indicator of Social Sustainability. Soc. Nat. Resour. 2010, 23, 401-416. [CrossRef]

12. National Development Council. Time Line for Taiwanese Aging Society. 2021. Available online: https://www.ndc.gov.tw/ Content_List.aspx?n=695E69E28C6AC7F3 (accessed on 20 November 2020).

13. Hsiao, T.-H. From cultural and creative gilded to moral economic-The action of pinglin Taiwan blue magpie tea. In Graduate Institute of Building and Planning; National Taiwan University: Taipei, Taiwan, 2013; p. 184.

14. Gruenewald, D.A. The Best of Both Worlds: A Critical Pedagogy of Place. Educ. Res. 2003, 32, 3-12. [CrossRef] 
15. McInerney, P.; Smyth, J.; Down, B. Coming to a place near you? The politics and possibilities of a critical pedagogy of place-based education. Asia Pac. J. Teach. Educ. 2011, 39, 3-16. [CrossRef]

16. Chang, S.E. Blue Magpie TEAgriculture: Eco-tea Cultivation and Participatory Farming in Pinglin Satoyama, Taiwan. Procedia Soc. Behav. Sci. 2013, 101, 14-22. [CrossRef]

17. Hsiao, T.-H.; Su, Y.-C.; Hsu, H.-Y.; Yang, S.-S. Learning from Toyooka Satoyama Experiences: Oreintal Storck Revitalization Case Study; National Taiwan University: Taipei, Taiwan, 2012; p. 23.

18. Department of Statistics, New Taipei City. Available online: https://oas.bas.ntpc.gov.tw/NTPCT/Page/adsex1.aspx?sexorgno= 3210000 (accessed on 3 December 2020).

19. Kuo, M.-Y. Tea Household Entrepreneur of Pinglin-Cultivation of Crafts, and Lifestyles of Tea Farmer, Tea Master, and Tea Merchant. Master's Thesis, Graduate Institute of Building and Planning, National Taiwan University, Taipei, Taiwan, 2016.

20. Huang, R.-L. Multiple Interpretation and Social-spatial Construction of Pinglin's Soundscape. Master's Thesis, Graduate Institute of Building and Planning, National Taiwan University, Taipei, Taiwan, 2016.

21. Li, L.-W. Toward a Self-sustaining Energy Management Future: Participatory Planning for Low Carbon Communities. Master's Thesis, Graduate Institue of Environmental Engineering, National Taiwan University, Taipei, Taiwan, 2012.

22. Chiang, H.-H. Growing Tea or Making Nature: The Symbolic Struggle of the Wenshan-Pouchong Tea Production Field in Pinglin. Master's Thesis, Graduate Institute of Building and Planning, National Taiwan University, Taipei, Taiwan, 2016.

23. Yang, Z.-J. Food Quality and Landscape Transformations: A Case Study of Wenshan-Pouchong Tea Industry in Pinglin, Taiwan Master's Thesis, Graduate Institute of Building and Planning, National Taiwan University, Taipei, Taiwan, 2016.

24. Chen, L.-C.; Chang, S.E. Building and Recovering Rural Economic Landscapes: The case of liquor and tea industries in Taiwan. Procedia Soc. Behav. Sci. 2015, 202, 408-416. [CrossRef]

25. Kawai, A. Prospect for Integrated Pest Management in Tea Cultivation in Japan. J. Agric. Res. Quartly 1997, 31, $213-217$.

26. EPA. Integrated Pest Management (IPM) Principles. Available online: https://www.epa.gov/safepestcontrol/integrated-pestmanagement-ipm-principles (accessed on 3 January 2021).

27. Lin, W.-K. The Effect of Tea Tasting Contest in Developing Local Tea Industry: A Case Study of Wenshan Baozhong Tea. Master's Thesis, Department of Agricultural Economics, National Taiwan University, Taipei, Taiwan, 2012.

28. Shenglin Chang's fieldwork notes from conversations with Mr. Lin during the studio class in Spring 2012.

29. Yang, C.-H. Is High Mountain Tea the Best? A Case Study of the High Mountain Tea Industry in Lishan, Taiwan. Master's Thesis, Graduate Institute of Building and Planning, National Taiwan University, Taipei, Taiwan, 2016.

30. Chang, C.-R.; Chang, S.E.; Suo, S.-B.; Chen, Y.-Y.; Wu, M.; Tsai, C.-F.; Hsieh, S.-Y. The NTU Agricultural Humanities Curricula Transformation Program Phase III; The project went through three phases; National Taiwan University: Taipei, Taiwan, 2019.

31. Kemmis, S.; McTaggart, R.; Nixon, R. The Action Research Planner Doing Critical Participatory Action Research; Springer: Singapore, 2014.

32. Chang, S.E.; Chen, Y.-Y. Knowledge ties in the emerging of place-based pedagogies. J. Des. 2020, 25, 43-64.

33. Fieldwork notes of Chang, S.E. from 2011 to 2013. The seven students dedicate in the Pinglin curricula the most. For those from Phase I (2012-2013).

34. Kuo, M.-Y.; Huang, R.-L.; Chiang, H.-H.; Kuo, Y.-R.; Huang, P.-C. TEAgriculture Lifestyles for New Ruralism Experiments: The Biodiversity Studio in Pinglin-Ayabe-Nara-Toyooka; National Taiwan University: Taipei, Taiwan, 2014; p. 79.

35. Rui, G.-Y.; Yang, Z.-J.; Yang, C.-H.; Tsai, Y.-P.; Chen, H.-W.; Kuo, M.-Y.; Huang, R.-L.; Pan, X.-R. Participatory Art Festival and Rural Revitalization: Xucun China and Pinglin Taiwan; National Taiwan University: Taipei, Taiwan, 2013; p. 121.

36. Reid, J.-A.; Green, B.; Cooper, M.; Hastings, W.; Lock, G.; White, S. Regenerating Rural Social Space? Teacher Education for Rural-Regional Sustainability. Aust. J. Educ. 2010, 54, 262-276. [CrossRef]

37. Mirochnik, E. The Centerless Curriculum. Teach. Educ. Q. 2002, 29, 73-78. 